\title{
Metallographical Aspects of the Application of Special Paint Layers for the Protection of Machine Part Sections against the Effect of lonitriding
}

\author{
Marius Bibu $^{1 *}$,and Florin Ciofu ${ }^{1}$ \\ ${ }^{1}$ Lucian Blaga University of Sibiu, Faculty of Engineering, Industrial Engineering and Management \\ Department, Romania
}

\begin{abstract}
The paper presents aspects concerning the appreciation of the protection through special paints based on copper powders used against plasma nitriding. First of all the choice of copper is motivated as an important metallic component of protecting paints, with the characteristics that the copper presents in the context of the physical and chemical phenomena (from the cathode and from gas volume) specific for the ionic nitriding process. The paper contains comparatively some characteristics (the duration of drying on the coat, the compatibility of the components, the capacity of extension and of avoiding the leakage, the power of covering, the capacity of joining, and the emitting of gases, the resistance in friction before and after the ionic nitriding, the way of obtaining the copper powder and its quality, the capacity of removing after ionic nitriding etc.) of the mixtures, for the protection against ionic nitriding. Following the researches on making more efficient technologies of local protection of metal pieces on certain areas with isolated layers against plasma nitride, the authors realized 2 different kinds of special original paints noted V-1 and V-2 used for this purpose. These paints are made having a basis of copper powder combined with magnesium oxide and polystiren dissolved in carbon chloride.
\end{abstract}

\section{Introduction}

In the machines manufacturing industry, there are often encountered situations when surface layers have to be improved (or reconditioned) by welding [1] or by heat treatments.

In the latter case, sometimes only a portion of a machine part needs to be treated and it would be wasteful to subject the whole part to a relatively material- and cost-intensive treatment such as ionitriding. In such cases, it is sensible to use a local protection technology, such as a special paint, to protect the nonfunctional segments of the machine part against the effects of ionitriding.

The study of elaborating technologies of metallic parts local protection against ionic nitriding was complete with obtaining some compositions or mixtures (pastes and paints)

*Corresponding author: marius.bibu@ulbsibiu.ro 
based on copper powders, which stop the absorption, the absorption and the nitrogen diffusion at/in the surface of the metallic parts during the process. (Bibu, 1998).

As it was mentioned, the copper that was used in the experiments was powder obtained either by electrolyte deposits (PCu 99.5 - I - copper powder, $1^{\text {st }}$ category, STAS 10283-80 - powder worked out when realizing the protection paste $\mathrm{P}$ ), either by physical dispersion in ball mill both meant for obtaining the special protective paints $\mathrm{V}-1$ and $\mathrm{V}-2$, [2].

This special protective paints (more efficient than the P paste), worked out from copper microscopic lamella in mixture with magnesia and dissolved polystyrene in carbon tetrachloride (noted with V-1, respectively V-2 than when polystyrene it is not used), applied on 39MoAlCr15 steel samples (Table 1), can firmly assure the protection of metallic surfaces on which they are deposed, stuttering their superficial hardness by stopping the nitrogen to penetrate during the ionic nitriding process.

Table 1. Composition of the 39MoAlCr15 steel sample

\begin{tabular}{|c|c|c|c|c|c|c|}
\hline Composition & $\mathrm{C}$ & $\mathrm{Cr}$ & $\mathrm{Mn}$ & $\mathrm{Mo}$ & $\mathrm{Si}$ & $\mathrm{Al}$ \\
\cline { 2 - 7 } 39MoAlCr15 & $0.35-$ & $1.35-$ & $0.30-$ & $0.15-$ & $0.17-$ & $0.70-$ \\
{$[\%]$} & 0.42 & 1.65 & 0.60 & 0.25 & 0.37 & 1.10 \\
\hline
\end{tabular}

The microhardness profiles in the superficial layer and in the section, of the samples mentioned before (protected, ionic nitrided, cleaned and degreased), made obvious the efficiency of the protection the elaborated paints assure, [2].

As well, another big advantage these paints assure is bound to the fact that they can be easily removed from the metallic surfaces protected after the plasma nitriding (cleaned or easily brushed).

The types of paints and special paints elaborated were selected from a very large number of combinations that were tested later, [2]. Further on are presented theoretically and experimentally a few observations concerning the copper as a basis compound of the mixtures used as protections against plasma nitriding.

\section{The copper conduct during the cathode spraying process}

Choosing the copper as a metallic element used to elaborate the special protective pastes and paints, is justified by a series of characteristics it represents in the context of physicalchemical phenomena (from the cathode and the volume of gases) specific to the process of ionic nitriding. The most important issue concerns the advantages offered by the copper during the cathode spraying in a very complex process.

The cathode spraying (the extraction or the evacuation of very fine particles from the surface material where takes place the discharge) is a process that can be analyzed from the physical point of view as well as from a chemical one, [3].

The bombing of the cathode by the positive ions determines on one hand a process of emission of some secondary electrons, but as well of some particles from the cathode composition (atoms, ions etc.), and on the other hand it is produced a "superficial activity" of the surfaces subdued to the general attack of the ionic bombing. This way the physical cathode spraying will take place on the protected surfaces, only on the surfaces of the paint layer (at the surface of the copper) and no way on the metallic surface of the samples. The result is the discharge by the impulse transfer from the incident particles, of some atoms from the superficial layer of the protective pellicle and not of the basis metal. Under this aspect the copper represents "a physical barrier", isolating the surface of the metal that must be protected by the ionic bombing.

Regarding the chemical cathode spraying, generally this represents a main compound of the steel plasma nitriding process and takes place when there is the possibility that the 
incident positive ions chemically react with the bombed material as it happens with the iron. The iron atoms are combining in the plasma of the luminescent discharge with the nitrogen that is in different states of excitations, making up this way the iron nitride, that is absorbed on the surface of ten cathode (on the surface of the part), following afterwards the absorption and diffusion processes.

The presence of the copper in the protection layer eliminates this chemical compound of the cathode spraying process, because at the temperature where the plasma nitriding takes place $\left(450 \ldots 600^{\circ} \mathrm{C}\right)$, there is not possible the make up of the copper nitride $\left(\mathrm{Cu}_{3} \mathrm{~N}\right)$, since it decomposes itself at the temperature of approximately $300^{\circ} \mathrm{C}$. The protective layers based on copper will refuse the nitrogen during the ionic nitriding process (a chemical barrier appears between the reacting medium and the surface of the part). This is one of the main special aspects that lead to the choice of the copper as a base metallic compound (of the same chemical and structural nature with the metallic stay that must be protected) of the elaborated protective mixtures.

Another important aspect related to the physical protection against plasma nitriding, is represented by the compactness of iron and copper crystal lattice regarding the stopping of the nitrogen diffusion as a consequence of ionic bombing. The copper represents a cubic network with centered surfaces (number of coordination 12), more compact than the iron's network which is cubic till $960^{\circ} \mathrm{C}$ with a centered volume (coordination number 8). As a consequence the clearances favorable to the diffusion are smaller in the copper's case that actually represents a higher value of the density $\left(\rho_{\mathrm{Cu}}=8.92 \mathrm{~g} / \mathrm{cm}^{3}\right)$, compared with that of iron $\left(\rho_{\mathrm{Fe}}=7.86 \mathrm{~g} / \mathrm{cm}^{3}\right)$.

\section{Technological characteristics of protection pellicles based on copper powder}

In a certain phase of the experimental researches was considered as acceptable the protection paste $P$, [2], obtained electrolyte copper powder ( $\mathrm{PCu} 99.5$ - I - copper powder, $1^{\text {st }}$ category, STAS 10283-81), dispersed in polystyrene varnish (polystyrene dissolved in carbon tetrachloride). This type of paste presents spongy dendrites formations, and through it the protection has a relatively low covering power (fig.1 and 2).

Checked during two cycles of ionic nitriding $\left(15\right.$ hours $/ 530^{\circ} \mathrm{C}$, and 30 hours $/ 530{ }^{\circ} \mathrm{C}$ ), was established that after making the macrodurity determinations HV 0,1 (in the superficial layer and in the protected samples area), that the protection is just satisfactory, the paste in this alternative, being recommended exclusively for parts with a very simple geometry (without many edges, points, steps etc.) and without high expectation from the protection.

As an argument in the favor of all mentioned above, it can be said that the side areas of the tested samples (at edges) the values of macrodurity vary between $900 \ldots 1000 \mathrm{HV} 0,1$, clear proof of insufficient protection.

The optimum alternatives for protection (the paints $V-1$ and $V-2$, fig.1,2), used the copper under the form of lamella (lamellar powder) of colloid or cvasicolloid (microscopic lamellae with values between $5 . .50 \mu \mathrm{m}$ ), obtained by milling in ball mill. In this state, the copper allows us to get very fine colloid suspensions (combined with the polystyrene varnish and the very fine technical magnesia oxide), the mixture obtained can be even and compact applied on metallic surfaces that need local protection on plasma nitriding. More, the main objective, the protection against the phenomena proper to the process, has been accomplished. 


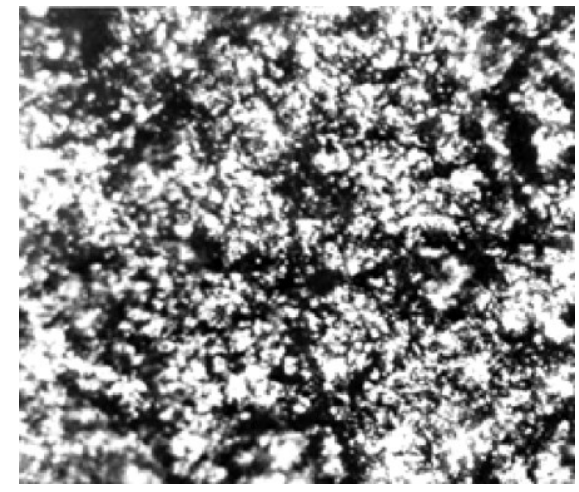

Fig.1. The layer's surface of the V-1 paint, (x40), after ionic nitriding (15 hours $/ 530^{\circ} \mathrm{C}$ ).

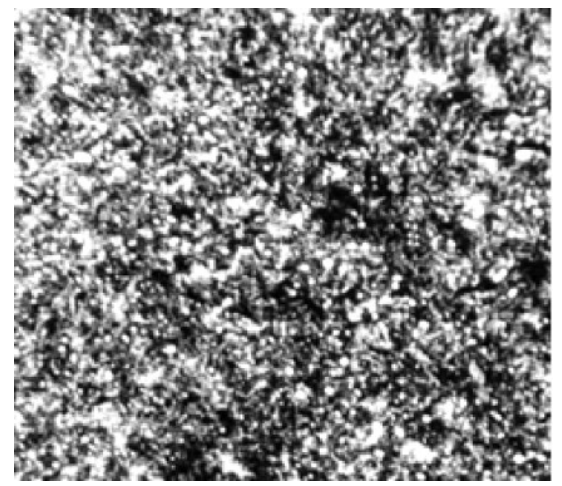

Fig.2. The layer's surface of the V-2 paint, (x40), after ionic nitriding $\left(15\right.$ hours $\left./ 530^{\circ} \mathrm{C}\right)$.

The researches supposed the checking at the beginning phase of the experiments, of the protective paints developed just in copper lamellar powder dispersed only in carbon tetrachloride, or copper lamellar powder dispersed only in polystyrene varnish. The mixtures did not offer the proper results from the point of view of the protection against ionic nitriding $\left(30\right.$ hours $\left./ 530^{\circ} \mathrm{C}\right)$, since the microdurities registered on the side areas of the samples (at edges) had values between $700 \ldots 1100 \mathrm{HV} 0,1$, and on the plane horizontal surfaces the determined macrodurities were of $250 \ldots 350 \mathrm{HV} 0,1$ (identical with those of the samples' core). This way it was possible to value that the efficiency of the mentioned combinations can be considered inadequate in the case of the parts with a higher geometrical complexity [4][5].

These alternatives of paints were supplementary checked during "tougher" regimes of ionic nitriding $\left(60\right.$ hours $\left./ 550^{\circ} \mathrm{C}\right)$, being noted locally a "superficial melting" of the copper particles. This phenomenon is due to the ionic bombing for a long time, the protective layer hardly could be removed at the end of the process, only in a very difficult way with a stripping brush, by sanding, or through mechanical working [5].

The subsequent use in the presented combinations of the magnesia oxide $-\mathrm{MgO}$ [4], lead to obtaining real performances from the special protective paints at plasma nitriding, performances that impose them on a wide use during the multiple industrial technologies of manufacture.

Table 2. Comparative characteristics of the isolating mixtures for local protection of the metallic parts against ionic nitriding process

\begin{tabular}{|c|l|c|c|c|c|}
\hline No & \multicolumn{1}{|c|}{ The characteristic } & $\begin{array}{c}\text { The paste } \\
\mathrm{P}\end{array}$ & $\begin{array}{c}\text { The paint } \\
\text { V-1 }\end{array}$ & $\begin{array}{c}\text { The paint } \\
\text { V-2 }\end{array}$ & $\begin{array}{c}\text { The } \\
\text { Nitrostop } \\
\text { Paste }\end{array}$ \\
\hline 1. & $\begin{array}{l}\text { The drying duration on layer } \\
\text { the number of necessary } \\
\text { layers) }\end{array}$ & $\begin{array}{c}8 \ldots 10 \mathrm{~min} . \\
(3 ; 4)\end{array}$ & $\begin{array}{c}2 \ldots 3 \mathrm{~min} . \\
(1 ; 2)\end{array}$ & $\begin{array}{c}2 \ldots 3 \mathrm{~min} . \\
(1 ; 2)\end{array}$ & $\begin{array}{c}2 \ldots 3 \mathrm{~min} . \\
(2)\end{array}$ \\
\hline 2. & $\begin{array}{l}\text { The components } \\
\text { compatibility }\end{array}$ & g. & v.g. & v.g. & g. \\
\hline 3. & $\begin{array}{l}\text { The stretching capacity } \\
\text { (homogenization) }\end{array}$ & g./s. & g. & g. & g. \\
\hline 4. & $\begin{array}{l}\text { The capacity of avoiding the } \\
\text { leaks and the edges slim }\end{array}$ & r. & v.g. & v.g. & g. \\
\hline 5. & \begin{tabular}{l} 
The covering power \\
\hline
\end{tabular}
\end{tabular}




\begin{tabular}{|c|c|c|c|c|c|}
\hline No & The characteristic & $\begin{array}{l}\text { The paste } \\
\mathrm{P}\end{array}$ & $\begin{array}{l}\text { The paint } \\
\text { V-1 }\end{array}$ & $\begin{array}{l}\text { The paint } \\
\text { V-2 }\end{array}$ & $\begin{array}{c}\text { The } \\
\text { Nitrostop } \\
\text { Paste }\end{array}$ \\
\hline 6. & $\begin{array}{l}\text { The capacity of adhesion to } \\
\text { the basis metal }\end{array}$ & g. & v.g. & v.g. & g. \\
\hline 7. & $\begin{array}{l}\text { The capacity of releasing the } \\
\text { gases }\end{array}$ & no & no & no & no \\
\hline 8. & $\begin{array}{l}\text { The resistance to abrasion } \\
\text { after drying (before ionic } \\
\text { nitriding process) }\end{array}$ & r. & g./s. & r. & s. $/ \mathrm{r}$. \\
\hline 9. & $\begin{array}{l}\text { The resistance to abrasion } \\
\text { after ionic nitriding process } \\
\text { (abrasion to the substrate) }\end{array}$ & r. & r. & r.r. & r.r. \\
\hline 10 & $\begin{array}{l}\text { The protection offered to the } \\
\text { metallic surface (maintaining } \\
\text { the structural, chemical } \\
\text { composition and hardness } \\
\text { characteristics) }\end{array}$ & $\begin{array}{c}\text { s. } \\
\text { (for regimes } \\
\text { of max.4 } \\
\text { hours) }\end{array}$ & $\begin{array}{c}\text { v.g. } \\
\text { (no matter } \\
\text { the duration } \\
\text { on the } \\
\text { keeping in } \\
\text { the regime) }\end{array}$ & $\begin{array}{l}\text { v.g. } \\
\text { (no matter } \\
\text { the duration } \\
\text { on the } \\
\text { keeping in } \\
\text { the regime) }\end{array}$ & $\begin{array}{c}\mathrm{g} . \\
\text { (for regimes } \\
\text { of } 7 \ldots 9 \\
\text { hours) }\end{array}$ \\
\hline 11 & $\begin{array}{l}\text { The way of obtaining the } \\
\text { copper powder }\end{array}$ & electro-lyte & ball mills & ball mills & ball mills \\
\hline 12 & $\begin{array}{l}\text { The quality of copper powder } \\
\text { (dimensions/ proportion on } \\
\text { the covered surface) }\end{array}$ & $\begin{array}{c}\text { Copper } \\
\text { powder PCu } \\
\text { 99.5, sort I, } \\
\text { STAS } \\
10283-88 \\
\end{array}$ & $\begin{array}{c}\text { microscopic } \\
\text { copper lamellae } \\
5 \ldots 30 \mu \mathrm{m} / \\
15 \ldots 80 \%\end{array}$ & $\begin{array}{c}\text { microscopic } \\
\text { copper } \\
\text { lamellae } \\
5 \ldots 30 \mu \mathrm{m} / \\
15 \ldots 80 \%\end{array}$ & $\begin{array}{c}\text { copper } \\
\text { lamellae } \\
30 \ldots 50 \mu \mathrm{m} / \\
30 \ldots 50 \%\end{array}$ \\
\hline 13 & $\begin{array}{l}\text { The complexity of the } \\
\text { protected parts geometry }\end{array}$ & $\begin{array}{l}\text { reduced/ } \\
\text { medium }\end{array}$ & $\begin{array}{l}\text { medium/ } \\
\text { very high }\end{array}$ & very high & high \\
\hline 14 & $\begin{array}{l}\text { The removal capacity after } \\
\text { ionic nitriding process }\end{array}$ & $\begin{array}{l}\text { very easy } \\
\text { (for regimes } \\
\text { of max.4 } \\
\text { hours) }\end{array}$ & $\begin{array}{l}\text { very easy } \\
\text { (no matter } \\
\text { the duration } \\
\text { on the } \\
\text { keeping in } \\
\text { the regime) }\end{array}$ & $\begin{array}{l}\text { very easy } \\
\text { (no matter } \\
\text { the duration } \\
\text { on the } \\
\text { keeping in } \\
\text { the regime) }\end{array}$ & $\begin{array}{c}\text { Easy } \\
\text { (for regimes } \\
\text { of } 7 \ldots 9 \\
\text { hours) }\end{array}$ \\
\hline
\end{tabular}

Notation: v.g. - very good; g. - good; s. - satisfactory; r. - reduced.

A few of the characteristics and properties of the pastes and paints based on copper powders, worked out, selected and recommended for using against enriching with nitrogen of the superficial layers of the metallic parts during the thermochemical treatment of plasma nitriding, are comparatively presented in the table 2 .

\section{Experimental results}

In order to emphasize those exposed above, we present the results of 3 experimental determinations: EXP.1, EXP.2 and EXP.3, which consisted in unfolding of 3 ionic nitride processes, applied differently for 3 categories of pieces (table 3). The experimental determinations were performed on sample from 39MoAlCr15 with dimensions $\varnothing 60 \times 10$ $\mathrm{mm}$.

In order to a more accurate appreciation of the effects of the isolation layers special elaborated for this purpose, we used tests completely rectified - $\mathrm{Sr}$, tests completely oxidated - So, and tests completely protected with paints $-\mathrm{Sp}$.

Considering these aspects, it is known that the global development of plasma nitride process follows 4 stages [2]. During the first period $-I_{1}$, it is realized the cleaning and 
preheating of pieces, phase in which the gas ions, bombing the pieces surfaces, cleans them of impurities and oxides etc., preparing them for the true ionic nitride. So, through catod pulvering is realized ionic cleaning of the pieces, period in which the frequency of transitions of light discharges in electric arcs is relative high. The second period, $\mathrm{I}_{2}$, corresponds to temperature increasing up to the regime temperature. The third period, $\mathrm{I}_{3}$, corresponds to ionic nitride, which takes place at constant temperature and pressure. The last period of the process, $\mathrm{I}_{4}$, is that in which the pieces are cooling in the recipient up to aprox. $200^{\circ} \mathrm{C}$, after which they are removed from the recipient and cooled at medium temperature.

Table 3. Experiments made for analyzing and evaluation of the ionic nitride process for cam axes local isolated on nonfunctional surfaces with special protection paints $\mathrm{V}-1$ and $\mathrm{V}-2$

\begin{tabular}{|c|c|c|c|}
\hline Experiment & Sample & $\begin{array}{c}\text { The surface } \\
\text { state of the sample }\end{array}$ & Observations \\
\hline EXP.1 & $\mathrm{Sr}$ & $\begin{array}{c}\text { Unprotected sample } \\
\text { (metal shine } \mathrm{Ra}=0,025 \\
\mathrm{~mm} \text { ) }\end{array}$ & $\begin{array}{l}\text { Regardless the state of surface- } \\
\text { rectified }(\mathrm{Ra}=0,025 \mathrm{~mm}) \text { or } \\
\text { oxidated - unprotected tests were } \\
\text { degreased before the process; }\end{array}$ \\
\hline EXP.2 & So & $\begin{array}{c}\text { Unprotected sample } \\
\text { (surface with oxides, slag } \\
\text { and irregularities) }\end{array}$ & $\begin{array}{c}\text { The paints layers were put on those } \\
\text { surfaces through brushing with } \\
\text { intermediate times of drying }\end{array}$ \\
\hline EXP.3 & $\mathrm{Sp}$ & $\begin{array}{c}\text { Protected sample } \\
\text { Thickness of paint layer : } \\
0,45 \mathrm{~mm} \\
<2 \text { paint layers }> \\
\text { (in the beginning, surface } \\
\text { with oxides, slag and } \\
\text { irregularities) }\end{array}$ & $\begin{array}{l}\text { Tests of steel } 39 \mathrm{MoAlCr} 15 \text {, } \\
\text { with dimensions } \varnothing 60 \times 10 \mathrm{~mm} \text {, } \\
\text { improved at } 28 \ldots 30 \mathrm{HRC} \\
\text { Ionic nitride regime : } \\
\mathrm{T}=550^{\circ} \mathrm{C} ; \quad \mathrm{p}=2.5 \mathrm{torr} \\
\mathrm{t}=12 \mathrm{~h}, \quad 25 \% \mathrm{~N}_{2} / 75 \% \mathrm{H}_{2} \text {. }\end{array}$ \\
\hline
\end{tabular}

It was interesting to observe the development of plasma nitride cycles of the cam axes, only during the phases $I_{1}$ and $I_{2}$, because on the ionic nitride period, the energy for maintaining at regime temperature of the zones protected with special paints $\mathrm{V}-1$ and $\mathrm{V}-2$ is with $10 \%$ bigger than that of the same areas, but unisolated at plasma nitride.

During the developing of ionic nitride cycles, in the experiments (EXP. 1, EXP. 2, EXP. 3 ), it was observed that the biggest part of the absorbed gases were eliminated up to the temperature of $150-220^{\circ} \mathrm{C}$. This is sustained by the fact that up to this temperature were observed a big number of transitions of light discharges in electric arcs.

It is obvious that this gas elimination phase could not be eliminated neither in the case of Sr sample or Sp sample, because both on unprotected metal surfaces and those protected of the pieces which were ionic nitrided there are absorbed ear, water vapors, oxygen (under the form of oxides), nitrogen, hydrocarbons and substances from the detergent washing or organic solvents. It is also possible that inside the axes may be absorbed gases from the previous processes of elaboration and thermal treatment $\left(\mathrm{H}_{2}, \mathrm{CO}, \mathrm{N}_{2}, \mathrm{O}_{2}, \mathrm{CO}_{2}\right.$, hydrocarbons, etc.) $[6,7,8]$.

When these disturbing factors disappeared, the elimination of gases process is reduced, the cam axes for ionic nitride are preheated in some degree. The following phase is that of effective heating up to the temperature of the stabile regime $\left(\mathrm{T}{ }^{(\mathrm{RS})}=550^{\circ} \mathrm{C}\right)$, followed by the ionic nitride process (period $\mathrm{I}_{3}$ ) which can be normal developed, for example for a period of 12 hours at the work temperature previously reached on the period $\mathrm{I}_{2}$.

In figures 3 and 4 are exposed in comparison the time variations of temperatures $-T_{m}$, $T_{t}, T_{p}$, of the unload tension- $U_{d}$ and of current density $-j_{m}, j_{t}, j_{p}$, for the 3 determinations, 
EXP.1...EXP. 3 presented in table 3 reffering to intervals $I_{1}, I_{2}, I_{3}$ of ionic nitride cycles of these experiments.

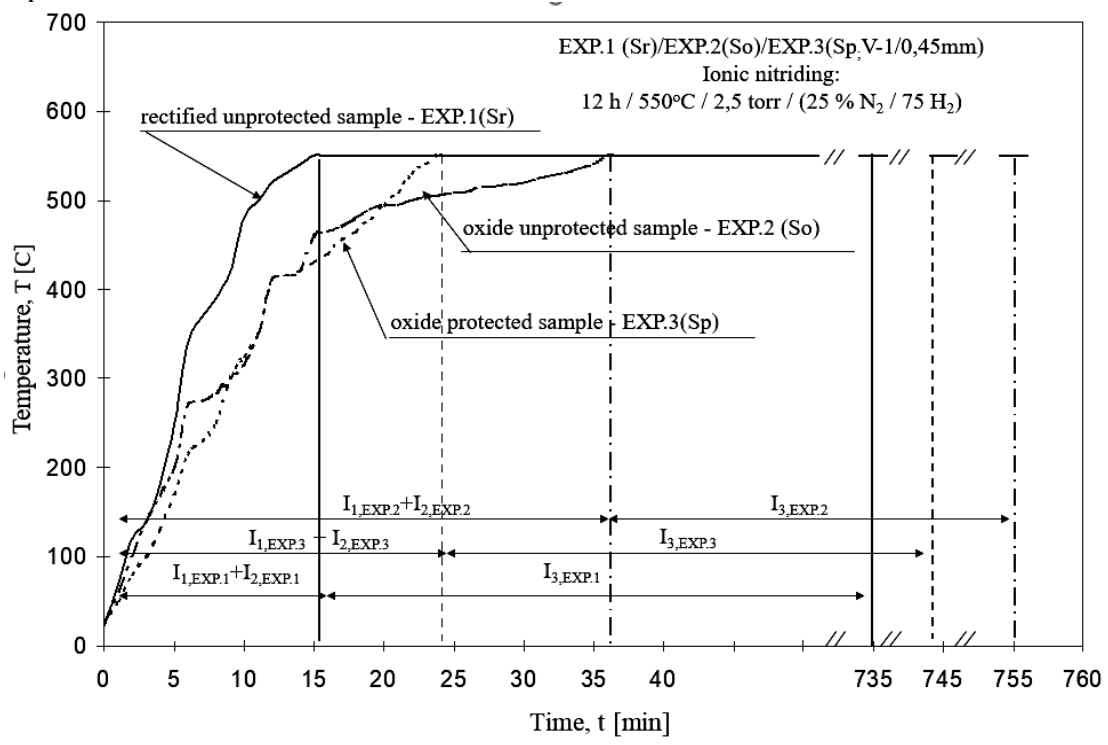

Fig. 3. Time variation of temperatures on intervals $I_{1}, I_{2}$ and $I_{3}$ during ionic nitride of protected and unprotected zones of cam axes for the experiments EXP.1, EXP 2 and EXP. 3

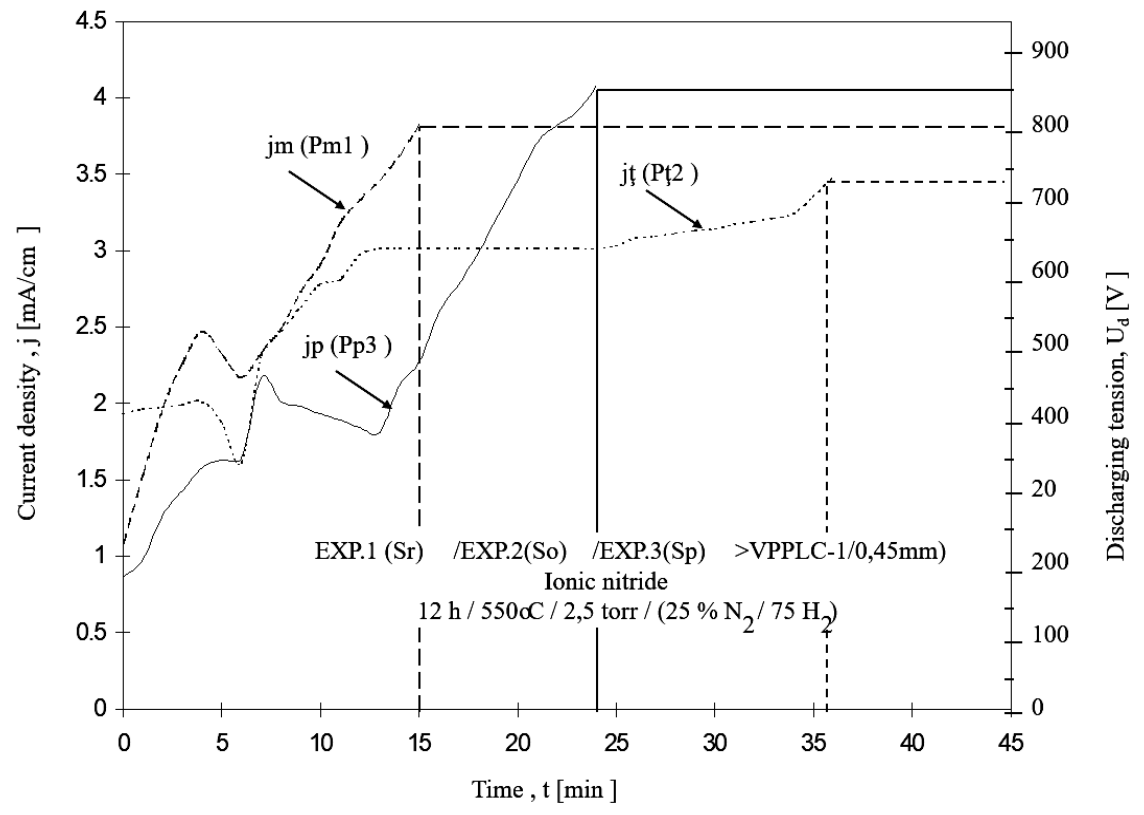

Fig. 4. Time variations of discharging tensions and current densities up to the stability of work regime at ionic nitride of protected and unprotected zones of cam axes for experiments EXP.1, EXP. 2, și EXP.3

Following our determinations it was concluded that the temperature and length of ionic nitride process are 2 technological parameters which are determined generally by the constructive conditions of the cam axes, their values being reflected in the depth and 
hardness of the nitrided plasma layers. For all the 3 experiments, the phases of elimination of gases - preheating (intervals $\mathrm{I}_{1}$ ) were completed around the temperature of $150 \ldots 220^{\circ} \mathrm{C}$.

\section{Conclusions}

All these observations, appreciation and conclusions, (resulted as a consequence of the made experimental determinations), were arguments in favor of recommending the two types of special protective paints $V-1$ and $V-2$, [2], for their use for local protection against the nitrogen diffusion during the ionic nitriding process.

The directions for research that were tackled, regarding this theme will be grouped in many distinctive categories and analyzed aspects regarding:

- the influence of process parameters (temperature, duration, composition and the gas pressure of work) on the structure, characteristics and the pastes or elaborated protection paints (and vice-versa);

- the influence of the protective pellicles on the quality (of the roughness) of the parts metallic surfaces where are applied, after the display of the thermochemical process and (vice versa), as well on the dimensional and form modifications of the protected and treated parts;

- the chemical composition influence of the isolating layers on the physical-mechanical properties, on the structure, tension state and initial chemical composition of the metallic surfaces protected and subdued to the process in discussion (and vice-versa);

- the protections influence on the fundamental processes at the cathode and in the volume of ionized gases during the process;

- the influence of the protective layers on the energy consumption, of the efficiency of an ionic nitriding installation.

\section{References}

1. Semenescu A., Babis C., Chivu O.R., Gligor A.M., Rev Chim-Bucharest, 8 (2016)

2. M. Bibu Doctor's degree thesis, "Lucian Blaga" University of Sibiu, Faculty of Engineering, Sibiu (1998)

3. H. Du, - "A New Thermodynamic Evaluation of Fe-N and Fe-N-C Phase Diagrams", Material Research Center, Royal Institute of Technology, Stockholm, TRITA-MAC-0511, 89 (1993)

4. M. Bibu, $12^{\text {th }}$ Romanian International Conference on Chemistry and Chemical Engineering (CIChICh - 2001), Faculty of Industrial Chemistry, "Politehnica" University of Bucharest, Romania, 184 (2001)

5. M.Bibu, $12^{\text {th }}$ Romanian International Conference on Chemistry and Chemical Engineering (CIChICh - 2001), Faculty of Industrial Chemistry, "Politehnica" University of Bucharest, Romania, 192 (2001)

6. F. Ciofu, Fiability and Durability,1, 137 (2012)

7. F. Ciofu, WSEAS Conference, MEQAPS '13, Braşov, 310 (2013)

8. D. Dobrotă, Journal of Adhesion Science and Technology, 27, Issue 2 (2003) 